could receive sensitive treatment and analysis and many cases were referred. Being the fulcrum of this effort was a great burden to him. He could see how doctors could be sucked in to the process of wrongdoing by an effort to care, but then become besmirched by it.

His post retirement years were spent, as indeed most of his life was spent, in Oxford. He went there originally from Christ's Hospital as a War Memorial scholar to University College. Then, after training in paediatrics and being influenced by Donald Court, he served in the RAF but returned to be the registrar, and the life-long friend, of Victoria Smallpiece. Later he became her research assistant in paediatric neurology and thus entered his first phase of productivity. A failure by the MRC to take over this project, as had seemed intended, after seven years of effort, deeply wounded him and imperilled his career. $\mathrm{He}$ and his family relied heavily on his working wife and she provided, then as subsequently, her loyal personal and professional support. Ian Skottowe realised his assets and he re-trained in psychiatry to become the only child and adolescent psychiatrist in the whole region to be based in a hospital; a hospital to which he brought international renown.

The death of his wife in 1988 broke an attachment which was of enormous personal and professional importance to him. They had had four children, two of whom became physicians, all of whom delighted him and informed his work.

DAVID C. TAYLOR

\section{GiUSEPPE PAMPIGLIONE, formerly Head of the Department of Neurophysiology, Hospital for Sick Children, Great Ormond Street, London}

After an eventful time as a medical student in Rome during which he edited an antifascist paper, organised students' demonstrations and managed to get himself arrested by the secret fascist police, Guiseppe Pampiglione qualified with a "summa cum laude" degree in 1942. By then, Pep, as he came to be known, had already decided to devote himself to neurology and neurophysiology and by 1948 had passed his postgraduate examinations in both subjects. Soon afterwards he obtained a travelling scholarship to study cerebral tumours in Paris where he also worked in the EEG Department at the Hospital of St Anne's. Later that year a British Council scholarship took him to the National Hospital, Queen Square.

Pep soon realised that the opportunities in this country were much greater than in post-war Italy and his considerable ability was quickly recognised. He became senior registrar in the EEG department of the National Hospital and later lecturer in clinical neurophysiology in the Institute of Psychiatry. Here, he worked on temporal lobe epilepsy in close association with Murray Falconer and actually took EEG recording from the surface of the brain at operation thus helping to localise the lesion.

The late Sir Charles Symonds, who had befriended him and was most anxious to keep him in this country, advised him to obtain a British qualification and helped him to enter Guy's Medical School as an undergraduate.

A ludicrous situation arose whereby Pep was awarded the MRCP on published work before he had passed his qualifying examinations. At Guy's he taught neurology/neurophysiology to his fellow undergraduate students and in 1956 he was appointed Head of the Department of Neurophysiology at the Hospital for Sick Children, Great Ormond Street before he had actually completed his pre-registration jobs!

For a while Pep combined the above post with that of a consultant psychiatrist at the Royal Free and also for a time at Charing Cross Hospital, but it was his work at Great Ormond Street which was to make his international reputation.

Pep proceeded to the FRCP in 1969 and served as president of the Comparative Medicine Section at the RSM on two occasions. He was also president of the EEG Society and lectured widely both nationally and internationally. He was a visiting professor in the United States, in Germany, in Italy and in China and was elected vice president of the International Federation of EEG and Clinical Neurophysiology and member of the Association of British Neurologists. He was a founder member of the Association of British Clinical Neurophysiologists (for a while served as its president) and of the Biological Engineering Society. He was an honorary member of practically all EEG and Neurophysiological Societies and was on the editorial committees of many learned journals.

Pep had the highest standards for himself which he projected on those around him. Some did not find him an easy colleague for he could be stubborn and argumentative in committees and others sometimes thought him a hard task-master but all respected him for the care and devotion he gave to his department and to his young patients as well as for his honesty and his integrity. He had wide interests, was a good host and a stimulating companion.

He leaves a wife, a daughter and two sons, the eldest of whom is a consultant obstetrician and gynaecologist.

Silvio BeNaIM

Humphrey Richardson, Consultant Psychiatrist, The Royal Victoria Infirmary, Newcastle upon Tyne

Dr Humphrey Richardson died on his 69th birthday on 14 December 1992 following a lengthy and stoic struggle with complications of diabetes. 